\title{
"Oh, Dignity too?" Said the Robot: Human Dignity as the Basis for the Governance of Robotics
}

\author{
Lexo Zardiashvili $^{1}$ iD $\cdot$ Eduard Fosch-Villaronga ${ }^{1}$
}

Received: 14 October 2019 / Accepted: 21 December 2019 / Published online: 7 January 2020

(c) The Author(s) 2020

\begin{abstract}
Healthcare robots enable practices that seemed far-fetched in the past. Robots might be the solution to bridge the loneliness that the elderly often experience; they may help wheelchair users walk again, or may help navigate the blind. European Institutions, however, acknowledge that human contact is an essential aspect of personal care and that the insertion of robots could dehumanize caring practices. Such instances of human-robot interactions raise the question to what extent the use and development of robots for healthcare applications can challenge the dignity of users. In this article, therefore, we explore how different robot applications in the healthcare domain support individuals in achieving 'dignity' or pressure it. We argue that since healthcare robot applications are novel, their associated risks and impacts may be unprecedented and unknown, thus triggering the need for a conceptual instrument that is binding and remains flexible at the same time. In this respect, as safety rules and data protection are often criticized to lack flexibility, and technology ethics to lack enforceability, we suggest human dignity as the overarching governance instrument for robotics, which is the inviolable value upon which all fundamental rights are grounded.
\end{abstract}

Keywords Human dignity · Governance · Robotics · Human-robot interaction · Healthcare robots

Lexo Zardiashvili

a.zardiashvili@law.leidenuniv.nl

1 eLaw Center for Law and Digital Technologies, Leiden University, Leiden, The Netherlands 


\section{Introduction}

Progress in science and technology makes our lives more comfortable and extended. Prolonging our lives increases our chances to live more experiences and to contribute in more ways to our society, but it also makes us largely dependent on healthcare (WHO 2018). Due to the demographic regression in developed countries and the number of persons who may potentially take care of older adults and contribute to the health and social systems is dramatically shrinking. According to the World Health Organization, the proportion of the world's population over 60 years will nearly double from 12 to $22 \%$ between 2015 and 2050 (WHO 2018). At the same time, statistics show that significant neurological disorders such as autism spectrum disorder (ASD), and debilitating conditions such as obesity, or Parkinson's are on the rise (Tapus et al. 2019).

The integration of robots in healthcare provides a practical, complementary solution to address the demand raised by the shortage of healthcare professionals and promises safer, more efficient, and personalized care. For instance, robots might be presented as the solution to bridge the loneliness that elderly or disabled persons often experience. On the other hand, European Institutions acknowledge that human contact is an essential aspect of personal care and that the insertion of robots could dehumanize caring practices (European Commission 2018). Such instances of human-robot interactions raise the question to what extent the use and development of robots for healthcare applications can challenge the dignity of users (Vallor 2011; Sharkey 2014; Fosch-Villaronga 2019). Recent literature also highlights that technology might have unintended long-term harmful impacts on the human psyche, in particular on the way the brain works (Carr 2010) and the person's identity and self-respect, and this also questions whether these technologies are adequate for care purposes.

In this article, we solely focus on robotics, and look at different robot applications in the healthcare domain, with the particular lens of human dignity. Human dignity, a term often used in health (care) debate, also constitutes a legal concept that, to some extent, can be understood as the crucial minimum requirement for ensuring the protection of every individuals' self-respect in society. Healthcare applications of robots might support individuals in achieving 'dignity' and at the same time, pressure it. The objective of this paper is not to thoroughly analyze all the applications and conclude which applications violate 'human dignity,' but, instead, provide an overview of how these applications promote or pressure dignity.

In Sect. 2, we provide a brief historical overview of dignity. We elaborate on the core content of this legal concept and describe its various ethical conceptions. We discuss two (opposite) ways the use of robotics in healthcare can affect human dignity. While Sect. 3 lists various uses of robot-technology in healthcare that might promote human dignity, Sect. 4 analyzes the negative impacts such use might have on this concept. This latter section addresses how the use of robots in healthcare might lead to the objectification of individuals, how it may dehumanize healthcare practices, and may, in the long run, cause other long-term adverse 
effects, such as dependency. In Sect. 5, we evaluate the suitability of the current regulatory approaches concerning care robots. In the end, we close the article identifying dignity as an overarching legal concept from which legal frameworks should confine the regulation of the use and development of robots in healthcare.

\section{Human Dignity}

\subsection{Brief History of Dignity}

Human dignity is the inviolable value upon which all fundamental rights are grounded. Human dignity represents an existing legal concept, which has played an essential role in the adoption of constitutional documents globally as well as the development of human rights adjudication. The significance of human dignity as a legal concept became apparent during the adoption of the Universal Declaration of Human Rights (UDHR), and since then it has been one of the central concepts in the drafting of other human rights instruments (Dicke 2002) that have used the concept to prohibit, for instance:
A. Slavery (Assembly 1948);
B. Torture (Assembly 1948);
C. Inhuman or degrading treatment (Assembly 1948);
D. Forced labor (European Convention on Human Rights 1950);
E. Death penalty (ICCPR Second Optional Protocol 1989);
F. Extreme poverty (Vienna Declaration and Programme of Action 1993);

Some authors understand human dignity as the central value underpinning the entirety of international human rights law. While the European Convention on Human Rights (ECHR) (Council of Europe 2018) or the treaties of the European Union do not expressly mention it, the concept of human dignity has reared its head in the caselaw of the European Court of Human Rights and the European Court of Justice. It has been stated to be 'the very essence' of the ECHR and to constitute the value underlying European Union equality legislation (O’Mahony 2012). ECtHR now regards human dignity as underpinning all of the rights protected by the Convention (McCrudden 2008). Despite the large and erudite body of literature, there is little or no consensus as to what the concept of human dignity demands of lawmakers and adjudicators (O'Mahony 2012). 'Indeed, for all the importance and emphasis placed on human dignity in the text of international conventions, domestic constitutions, and court decisions, the elusive nature of the concept has led many commentators to argue that it is at best, meaningless or unhelpful, and at worst potentially damaging to the protection of fundamental rights (O’Mahony 2012).' 


\subsection{Minimum Core of Dignity}

In their book, "Dignity in twenty-first Century", Schroeder and Bani-Sadr (2017) state that 'it is difficult to write about dignity' and provides a summary of Western academic debates about the meaning of dignity, elaborating that '... [human dignity] has been described as powerful, yet useless and vague; arbitrary, yet addictive; elusive, yet widely used; groundless, yet revolutionary; of supreme importance, yet without a reference point.' Other scholars share their conclusion that dignity is too multifaceted as a concept to be captured in one essence. McCrudden (2008), whose article on 'Human Dignity and Judicial Interpretation of Human Rights' stands out as a reference point for legal scholars, argues that human dignity does not provide a universalistic, principled basis for judicial decision-making in the human rights context.

As McCrudden (2008) explains, drafters of the UDHR (that represent the first universal human rights instruments) were facing a problem that no theoretical basis, from the plethora of theories, could provide the justification for human rights (speculations on man's divine origin, immortal destiny) to satisfy the need to have sufficient consensus in order to move forward (McCrudden 2008). Jacque Maritain proposed a strategy to concentrate on agreeing first about what practices were necessary to be prohibited (see, for example, "list A-F" above) and then provided its justification with human dignity (Glendon 2001). While drafters first agreed that, for example, torture, should be prohibited, justification of such consensus with a flexible notion of human dignity enabled a 'concrete political agreement on a seemingly shared ground (Shultziner 2007). 'Seemingly,' because the different parties that took part in a constitutive act could conceive human dignity as representing their particular set of values and worldview.

This excursion in drafting history should not be understood as explaining that human dignity has no content. On the contrary, such content is the reason why Maritain's strategy worked in the first place. While the application of dignity is widely divergent and has the perplexing capacity to pull in several directions, McCrudden acknowledges the feasibility to distill a minimum content of human dignity that has been applied universally and borrows three elements from Neuman (2000) to outline what he calls the 'minimum core' of human dignity. These elements are:

1. Every human being possesses an intrinsic worth, merely by being human;

2. Intrinsic worth should be recognized and respected by others, and some forms of treatment are inconsistent with respect for this intrinsic worth;

3. The state exists for individual human beings (not vice versa). 


\subsection{Conceptions of Dignity}

In other words, human dignity is a linguistic-symbol that resembles a belief in the intrinsic worth of humans that they derive by merely being human (Schroeder and Bani-Sadr 2017). Such belief, therefore, has been established as the explicit universal legal principle, that among other things, transcends any particular conflicts with ideologies. Only in Western philosophy, there are myriad conceptions ${ }^{1}$ of human dignity grounding it in humanity's divine creation, or rational autonomy, social recognition of each other's value, or unique ability to exercise control over the environment (Schroeder and Bani-Sadr 2017). Some may argue that human dignity is even 'anthropo-eccentric,' seeing humans 'strange' and 'incomplete,' rather than 'superior' species (Floridi 2016). Nevertheless, whatever is the standpoint of a viewer, the concept of human dignity transcends conflicts and makes a belief in human exceptionalism universal to human rights and law in general (McCrudden 2008).

Human dignity is timeless - an everlasting value that defines human nature and adaptable - ever-evolving with the ideas of what constitutes being human (Weisstub 2002). Human dignity can be seen as a universal concept that sums up the human's relation to himself, to others, its environment, and the universe. The way humans interact with robots can to some extent influence how human beings see themselves, influencing a shift of the sense of autonomy (privacy, self-determination), as well as self-respect (sense of self-worth), which triggers the need for the discourse on the concept of 'human dignity' and how the relationship between humans and robot technology pressures it. Recent technological advances meant to interact with humans may require us to rethink what human dignity involves, and use strategic adaptability of the concept to regulate the use of robots in healthcare, possibly by further regulatory intervention.

\subsection{Healthcare Robots from the Lens of Human Dignity}

The insertion of healthcare robotics raise the question of whether such technologies are beneficial for the users, or they are a mere reflection of a foolish road to more cost-effective care. Sharkey (2014) published an article on 'considerations of the robot care on the dignity of older people' through the lens of Capability Approach referring to the work of Nussbaum (2009) and discussing the 'unsolved' question of disability in the context of human dignity. Nussbaum (2009) argues that the goal of social justice should be to ensure that all humans achieve a threshold level of all of the capabilities. What this approach entails, is that although dignity (equal worth) is inherent for each individual, some do not have capabilities (mental or physical) to maintain it independently. For instance, a person with severe mental impairment (e.g., older people with dementia or Alzheimer's) might not be able to satisfy their basic needs. In these cases, protecting human dignity must be a positive obligation

\footnotetext{
${ }^{1}$ Concept vs. conception: concept—what exists; conception—why it exists (what exists) (see McCrudden 2008).
} 
for the state, to ensure that these people in question get the help they need to achieve the minimum level of self-respect and self-worth, guaranteed by human dignity.

Building on Sharkey's (2014) findings, we are extending the discussion to other care applications of robot technologies. Assistive robotics can take many forms. For example, they can be used as a platform for upper-limb rehabilitation (Pulido et al. 2019), as a tool to encourage infant leg-motion training (Fitter et al. 2019), or to teach students with intellectual disabilities (Reardon et al. 2019). While such applications can be helpful in a myriad of positive ways, they may cause to elevate feelings of loneliness, impair autonomy, and adjust a person's sense of self, that may challenge the concept of human dignity and result in its violation.

\section{Robots Promoting Dignity}

The United Nations Convention on the Rights of Persons with Disabilities (United Nations 2007) was born 'to promote, protect and ensure the full and equal enjoyment of all human rights and fundamental freedoms by all persons with disabilities, and to promote respect for their inherent dignity.' Although existing such a Convention, it is often unclear how those general principles translate into concrete actions.

In this section, we explore how various applications of robot technology may have the potential to realize the principles enshrined in the Convention's Art. 3, which focus on the respect for inherent dignity, individual autonomy including the freedom to make one's own choices, and independence of persons with disabilities; non-discrimination; full and effective participation and inclusion in society; and accessibility, among others.

For this purpose, we concentrate on the following list of applications of robots:
A. Feeding robots;
B. Robots for blind;
C. Exoskeletons;
D. Sex robots;
E. Therapeutic robots;

\subsection{Feeding Robots}

Having a meal together with family and friends is often taken for granted by many, but has a high impact on the morale of those with disabilities, including those who have problems with their upper-limbs, stroke patients, Parkinson's, or dementia (Canal et al. 2016; Herlant 2018). People with disabilities sometimes need assistance in feeding. Assisted feeding is the process of feeding a person who cannot otherwise feed themselves. Human assisted feeding is very time-consuming, and little attention is often given to it (Tsang 2008). Moreover, the feeding process turns into a caregiver-patient interaction, which now needs to coordinate in procedure and execution (Athlin et al. 1990) something that normally prevents patients from enjoying their meal (Martinsen et al. 2008). 


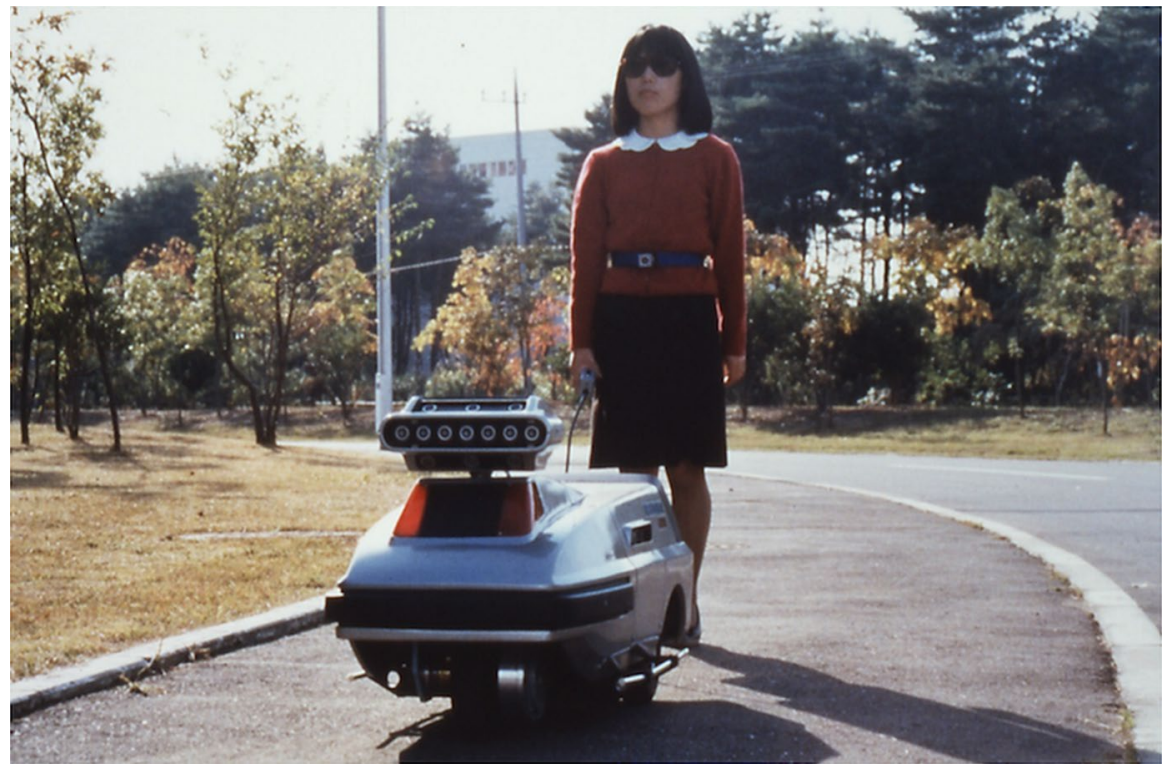

Fig. 1 Guide Dog Robot, MELDOG Project from the TachiLab (see Guide Dog Robot (MELDOG) from TachiLab, https://tachilab.org/projects/meldog.html)

In this respect, some engineers support the idea that 'using a robotic feeding device would allow for increased privacy and intimacy during mealtime' (Herlant 2018). The incorporation of robotic arms in tables, or in robotic wheelchairs with a feeding function could give patients back their dignity (Leroux and Labruto 2012). Robotic feeding devices may help people with disabilities live more independently and participating in social life without the need of having a human carer. In such a case, it seems that the robot would promote dignity in caring practices, as it would allow a patient to eat alone or accompanied, as any other person would do.

\subsection{Guiding Robots for the Blind}

Some researchers envisioned in the late 1970s the development and use of service robots for supporting human navigation for the impaired (Fig. 1).

The MELDOG Project developed the 'Guide Dog Robot,' a robot that could assist a blind master in navigation, and set a precedent for future research (Tachi and Komoriya 1984). During the following years, the literature was rich in advances pointing to a similar direction (Lacey and Dawson-Howe 1998), although the technology has yet to be mainstream.

Guiding robots for the blind could improve users' confidence, autonomy, and independence, thus increasing their sense of self-respect and promote their dignity. Having a robot could also be the right solution for those who cannot afford to have an assistance-trained dog or those that do not want to have the responsibility of taking care of a dog. Guiding robots could be mass-produced, affordable, 


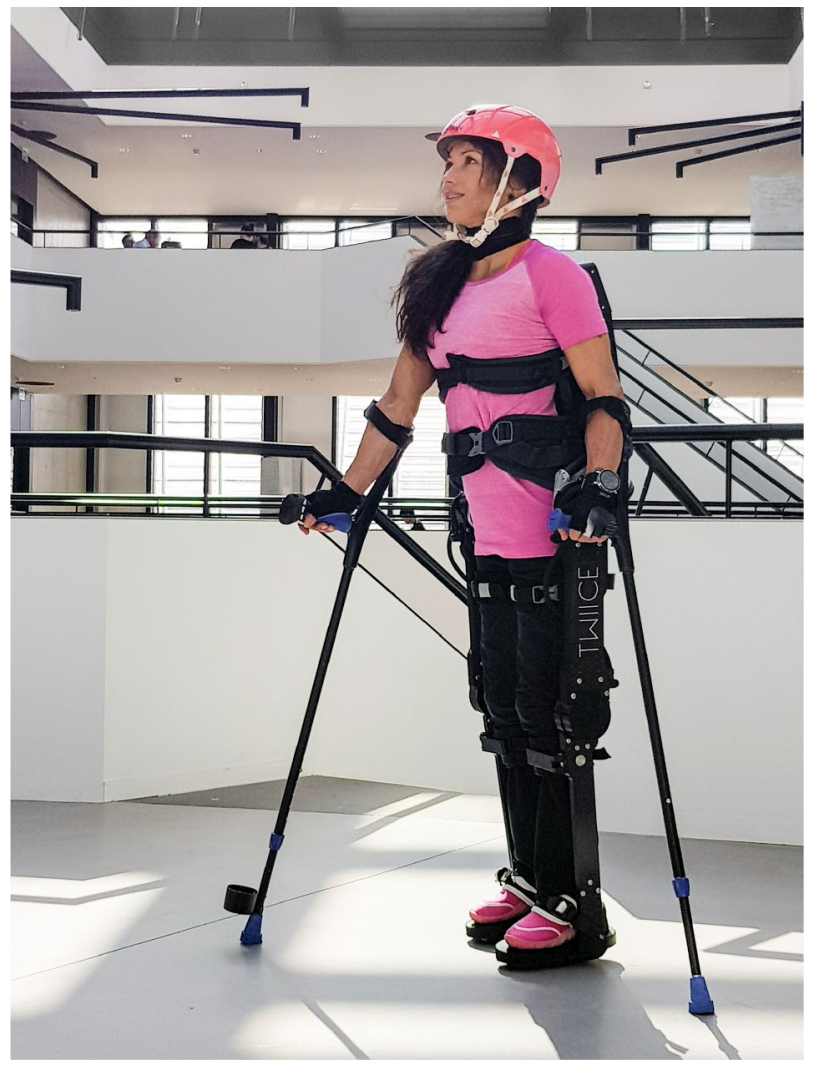

Fig. 2 Lightweight exoskeleton from TWIICE (see http://twiice.ch/, last accessed October 9, 2019)

low-maintenance, and could incorporate communication capabilities beyond mere navigation.

Guiding robots could replace assistance dogs, those dogs specially trained to assist persons with disabilities such as the visually impaired, or persons with neurological disorders, and those who need psychiatric assistance (Howel et al. 2017). However, while available studies focus on the benefits dogs may have on humans, there is not much research on assistive dogs' welfare (Bremhorst et al. 2018). On the contrary, the available evidence suggests that using punishment in pet dog training is associated with undesirable behaviors and potentially adverse welfare outcomes. For now, it is unclear how assistance dog trainers use punishment or whether such punishments have long-term adverse effects on them (Bremhorst et al. 2018).

Although the scope of this paper is the concept of human dignity, it is worth mentioning that having robots instead of dogs assisting the blind could indirectly help realize the rights dogs have as sentient beings. More research is needed to understand animal welfare, as in the EU context mostly relates to food safety (Broom 2017). 


\subsection{Regaining the Ability to Walk}

An exoskeleton is a wearable robot attached to the wearer's limbs to replace or enhance their movements. The majority of these exoskeletons are fastened directly to the user's body and work together 'in seamless integration with the user's residual musculoskeletal system and sensory-motor control loops' to assist him/her with minimal cognitive disruption and required compensatory motion' (Tucker et al. 2017) (Fig. 2).

Exoskeletons are good helpers for the elderly unable to sit, stand, or who need personal assistance at home, but they cannot afford human caregivers. Mainly, they are robotic devices that help users to help users stand up and walk again, which is a primary human function. Walking stabilizes blood pressure, improves pulmonary ventilation, prevents the degeneration of muscle and bone tissue, and increases joint mobility. Although there are wheelchairs that elevate the user up to the level of eye-contact, exoskeletons provide freedom to users and the possibility to do some exercise and increase muscle activity, which improves cognition abilities and oxygen flow to the brain. Exoskeletons can also be useful for rehabilitation. Human caregivers can help in the rehabilitation process of a person suffering from a spinal cord injury. However, human-based rehabilitation requires typically from three to five people actively involved. The use of exoskeleton technology can streamline such processes.

\subsection{Sex Care Robots}

Although every human should be able to enjoy physical touch, intimacy, and sexual pleasure, however, disabled people are often not in the position to fully experience the joys of life in the same manner as abled people. Similarly, older adults may have sexual needs that public healthcare tends to ignore as an essential part of their wellbeing (Lusti-Narasimhan and Beard 2013). In 1993, the United Nations stated that persons with disabilities should enjoy family life and personal integrity, and should not be denied the opportunity to experience their sexuality, have sexual relationships and experience parenthood' (UN 1993a, b, Rule 9, para. 2).

However, after more than 20 years of discussion, the universal access to sexual and reproductive health remains an unfinished agenda (Temmerman et al. 2014), as if society failed in recognizing people with disabilities as sexual beings (Maxwell et al. 2006). In this respect, there are authors that have begun to explore the potential use of sex robots for disabled care (Di Nucci 2017; Fosch-Villaronga and Poulsen 2019). The literature lacks a comprehensive understanding of the impacts of sex robots for care purposes and needs further exploration.

\subsection{Robot Therapists}

'In the good old days of Artificial Intelligence... we were writing the sentences on the blackboard and challenged one another to write a program that could "understand" them.' Colby (1981) remembered the early 1970s when he was working to 
develop a machine that could act as a therapist for paranoid patients. More than four decades have passed, and artificially intelligent robots (and/or virtual agents) are able not just to scrape the sentences from the blackboard, but also to 'isolate, capture, and render the most subtle and intimate behaviors, from an inadvertent blink to a jaw that slackens in surprise for a fraction of a second' (Zuboff 2019). These 'robot therapists' can take on high-level therapeutic interventions that used to be offered exclusively by highly trained, skilled health professionals. Researchers from the University of Munich found that the benefits of such agents might include "new modes of treatment, opportunities to engage hard-to-reach populations, better patient response, and freeing up time for physicians' (Fiske et al. 2019).

\section{Can robots Violate Human Dignity?}

Societal acknowledgment of human being's 'worth' is at the core of the concept of human dignity. However, certain practices might disregard this 'worth' or 'value' of human beings and, therefore, there might be a need for protection against such practices. Moreover, not foreseeing or anticipating potential adverse consequences might also affect human dignity. In the following subsections, we attempt to identify what robots, which practices, and what consequences risk disregarding this 'value' of being human.

\subsection{Risk of Objectification by Challenging the Patient Autonomy}

Human dignity as a 'value' entails that human beings cannot be treated like objects (Dworkin 2011). As Nussbaum (2009) suggests, objectification entails treating the person as lacking in autonomy or self-determination. One of the most challenging aspects of using robots in mental health practices is how to enable and respect the autonomy of a patient (Childress and Beauchamp 2001). Autonomy can be challenged, for instance, when a person with intellectual disabilities cannot understand what a robot is or what it does, therefore, cannot give fully informed consent, risking not only privacy infringement and manipulation, but even coercion (Vandemeulebroucke et al. 2018). The lines where help and monitoring can become manipulation and coercion are often blurred in theory and practice (Fiske et al. 2019). Hence, using robots as therapists (discussed in Sect. 3.5), as an assistant for the blind (discussed in Sect. 3.2), or sex robots (discussed in Sect. 3.4) challenges patient autonomy and risks their objectification. The extent to which 'suspension of disbelief' induced by the anthropomorphization of a robot caregiver leads to deception, and consequently violates human dignity, needs further investigation.

\subsection{Risk of Dehumanized Practice}

Weizenbaum (1976) highlighted that it was unethical using machines to listen, to understand, and to change, human emotions. Nowadays, research continues to suggest the importance of the human element in care and therapeutic practices 
(European Parliament 2017; Fiske et al. 2019). In general, therapeutic relationships are prone to the risk of transference of emotions, thoughts, and feelings from a patient to a therapist. Similarly, such transference might occur towards robots. As it is unknown whether robot therapists will ever be able to deal adequately with such transference, pressure on 'human dignity' remains in question (White and Parotto 2019).

The European Parliament (2017) recently warned about the possibility to dehumanize caring practices if human contact in sensitive contexts such as care is to be replaced by robot technologies. However, from care to sex robots, several companies claim that robots combat loneliness. Robots can be the interface that connects older adults that might live alone and might have relatively little human contact with the real world. The assumption that humans might be the best option to assist users and that the insertion of care robots might dehumanize caring practices is recurrent (European Parliament 2017). Dehumanization, while providing health care, suggests treating patients as if they lack mental capacities that we enjoy as human beings. As Herbert Kelman argues, being human has two features: 'identity' - or a perception of the person 'as an individual, independent and distinguishable from others, capable of making choices' and 'community' - a perception of the person as 'part of an interconnected network of individuals who care for each other'. Therefore, if an aspect of the community is taken away, this might challenge the dehumanization of health care practices risking violation of the legal concept of human dignity.

\subsection{Risk of Loneliness-Robots May Cause the Problem They Try to Solve}

Robots may allow older adults and persons with disabilities to be in touch with relatives, talk to doctors, or do grocery shopping. In other contexts, men and women rejected sexually by other men, or women might find comfort and company with a robotic sex doll. A sex doll will unlikely reject a person for his or her appearance and might serve the desires of the person without opposition. A different question may arise; nevertheless: could the continuous use of care or sexual companion robots intensify and reproduce the loneliness they try to bridge? Could therapeutic robots for children with autism isolate users and intensify even more their disorder (Howard et al. 2019; Fosch-Villaronga and Albo-Canals 2019)?

\subsection{Risk of III-Being, Dependency and Other Considerations}

Recent research suggests that technology use might have harmful effects on children and adolescents in particular (Rosen et al. 2014; Carr 2010). In a study including 1030 subjects (338 children, 316 pre-teen, and 376 teenagers), Rosen et al. (2014) concluded that not only unhealthy eating, lack of physical sport but also technology overuse predicts ill-being. In their study, Rosen et al. (2014) investigated whether certain types of technology including Internet, email, IMing/chatting, cellphone, video games, music players or technological toys had an impact on four different categories of ill-being, including physical problem symptomatology, psychological symptom manifestation, attention problems, and home and classroom behaviors. Children using technology 
presented total ill-being, as well as attention and physical problems. In particular, children using music players and technological toys predicted more ill-being; and preteenagers using email, cell phones, video games, and technological toys predicted more ill-being than those not using technology. For teenagers, it appeared that the overuse of any technology significantly predicted ill-being.

The conclusion of Rosen et al. (2014) was that technology use might have harmful effects on children and adolescents, and healthier food and more exercise might not be enough to improve their wellbeing. There is no reason to believe why robots might not have a similar impact on the wellbeing of users, including children, adolescents, older adults, and persons with disabilities (Fosch-Villaronga 2019). Similar to what happened to screens and phone usage, some may argue, however, that until robots become mainstream, we might not be able to see the impact they have on us (Palmerini et al. 2014).

Roboticists individually program robots to create, support and maintain more extended engagement because it not only improves usability, more engagement leads to better results (Howard et al. 2019). However, establishing and maintaining longterm engagement (Leite et al. 2013), might create a dependency of robot technology. More longitudinal studies are much needed to help understand what the consequences and byproduct effects of the use and development of robot technology are (FoschVillaronga and Albo-Canals 2019). As Fiske et al. highlight, 'the impact of intelligent robots on relationships, both human-robot and human-human relationships, is an area that requires further probing, as do potential effects on identity, agency, and self-consciousness in individual patients' (Fiske et al. 2019).

\subsection{Robot Technology Pressures Dignity}

In the above subsections, we identified significant challenges concerning respecting human dignity while using robot technology for healthcare purposes. Such challenges mostly arise from the risk of disregarding autonomy, therefore creating situations where a person can be treated as an object. Also, by taking out the 'human' element from care, they risk dehumanizing these practices. Fosch-Villaronga and Poulsen (2019) provided a list of care-related considerations in the table cited below, that summarizes some of the most pressing legal and ethical implications of the use and development of robots for care purposes (Table 1).

All the considerations referred to in the table put pressure on the concept of legal dignity, making it necessary for policymakers as well as developers to treat human-robot interactions with more care. Most importantly, further research in how each application corresponds with the inviolable belief in human dignity.

\section{Regulating Human-Robot Interactions for Healthcare}

Due to the novelty of practices and impacts seen in the above section, the development of robot technology may bring about unclear rules and areas of legal ambiguity (Fosch-Villaronga and Heldeweg 2018). In this respect, across the globe, industry representatives, governments, academics, and civil society are 
Table 1 Care-related issues for care robots

\begin{tabular}{ll}
\hline Care-related considerations & Explanation \\
\hline Human-robot safe interaction & $\begin{array}{c}\text { Robots may challenge the physical and mental integrity of the } \\
\text { users. Both physical and cognitive safety should be protected } \\
\text { Depending on the degree of control a user has, the question of who } \\
\text { is responsible if something goes wrong may abound } \\
\text { Allocation of responsibility } \\
\text { Privacy and data protection loss } \\
\text { may challenge the protection of their data protection and privacy } \\
\text { rights } \\
\text { Task delegations from the human to the machine risk overriding } \\
\text { the autonomy and independence of a person } \\
\text { Mimicking life-life and human states may lead to questioning the } \\
\text { authenticity of the relationship and deceive of the user. Robots } \\
\text { may encourage the idea elders (with dementia) go through a } \\
\text { second childhood } \\
\text { Insensitive use of robots risks treating elders as if they were not } \\
\text { sentient beings }\end{array}$ \\
Objectification and loss of control & $\begin{array}{c}\text { Human-robot interaction may exacerbate existing elder loneliness } \\
\text { and increase neglection by relatives and society }\end{array}$ \\
Human-human interaction decrease & $\begin{array}{l}\text { Technology, including robots and AI, may have long-term conse- } \\
\text { quences that might be difficult to foresee before mass-adoption } \\
\text { and continuous use }\end{array}$ \\
\hline
\end{tabular}

debating where legal-regulatory frameworks are needed and when, if ever, ethical or technical approaches suffice. The issue of the extent to which our existing ethical and regulatory frameworks cover sufficiently the impact of these technologies, however, still remains. In recent years, such opposing clash of worldviews has created a substantive body of academic work, discussing how to govern robotics or how to shape the course of technology-induced and ongoing social transformation. Academics and regulators are struggling to keep up with the number of articles, principles, regulatory measures, or technical standards produced on governance of emerging technologies (Cath 2018).

In this section, we compile frameworks addressing different aspects of human-robot interactions aiming to protect users against the adverse impacts of using robot technology. In Europe, these impacts tend to be addressed through safety regulations, data protection legislation, and technology ethics. In particular, we focus on the extent to which they contribute towards the protection of 'human dignity.' First, we describe how safety rules protect dignity; second, how data protection rules try to regulate impacts on an individual's privacy for safeguarding human dignity. Third, we look at how the Ethics Guidelines from the European High-Level Expert Group on Artificial Intelligence (appointed by the Commission in June 2018) (High-Level Expert Group on Artificial Intelligence 2019) addresses the impacts on dignity arising from robot technology. In the last section, we provide an insightful, new perspective on how to regulate human-robot interactions from the lens of human dignity. 


\subsection{Safety}

Cicero already said many years ago that the safety of the people should be the highest law. Oxford dictionary (2019) defines safety as the "condition of being protected from or unlikely to cause danger, risk or injury." Risk, on its side, is defined by "ISO 12100:2010 General Principles for Design-Risk Assessment and Risk Reduction" as the "combination of the probability of occurrence of harm and the severity of the harm." As such, safety is considered one of the most pressing issues among human-robot interaction experts (Fosch-Villaronga et al. 2019). The most general framework for safety involving robots quoted by legal scholars is the three laws of robotics of Isaac Asimov's (Leenes and Lucivero 2014):

1. A robot may not injure a human being or, through inaction, allow a human being to come to harm.

2. A robot must obey the orders given by human beings, except where such orders would conflict with the First Law.

3. A robot must protect its own existence as long as such protection does not conflict with the First or Second Laws.

Although initially three from Runaround in 1942, in 1986, a fourth law (that would be the zeroth law) was introduced by the same author in the Foundation of Earth:

0. A robot may not harm humanity, or, by inaction, allow humanity to come to harm.

Although part of science fiction, the European Parliament (2017) took this framework very seriously and suggested that they "must be regarded as being directed at the designers, producers, and operators of robots, including robots assigned with built-in autonomy and self-learning, since those laws cannot be converted into machine code". Nevejans (2016) argued, however, that Asimov wrote these laws in a certain moment in time, pseudo-legally, explaining how humans would remain in control if robots would take over. The European Parliament seemed, however, to misinterpret the true meaning of the laws, which established more of a kind of machine ethics rather than directed to roboticists (Nevejans 2016), although like other aspects like privacy (Koops and Leenes 2014) they may prove very difficult to be encoded.

A better point of departure could be the fundamental right to physical and psychological integrity. However, the European Parliament (2017) makes no references to it. Instead, the resolution states "the guiding ethical framework should be based on the principles of beneficence, non-maleficence, autonomy and justice, on the principles and values enshrined in Article 2 of the Treaty on European Union and in the Charter of Fundamental Rights, such as human dignity, equality, justice and equity, non-discrimination, informed consent, private and family life and data protection." In another part of the resolution, the Parliament stresses that "human dignity and autonomy_-both physical and psychological—is always to be respected." 
In this respect, "to guarantee a high level of product safety and consumer protection" the resolution redirects to safety standards, although it does not refer to already existing standards, such as ISO 13482:2014. Although this reference to private standards may revive the discussion on balance between legitimacy and effectiveness of techno-regulations (Fosch-Villaronga and Heldeweg 2018; Fosch-Villaronga and Golia 2019), this is, for now, the only existing technical framework validated by all the members of the International Organization for Standardization (ISO), which include states and private bodies. The applicability of product liability laws and standards, however, might not be straightforward in the context of physically embodied robots comprising cyber-physical systems as 'product interconnected with services, (...) an inseparable mixture of hardware, software, and service' (FoschVillaronga and Millard 2019). Indeed, the notions of product, producer, and defect are challenging to define and detect in complex products with physical and informational elements. In a sense, these laws and technical standards reflect a moment in time when products did not interconnect with other devices or their environment and when robots did not interact with humans (they mainly were caged in industrial environments with little human contact).

\subsection{Data Protection Legislation for Regulating Human-Robot Interaction}

Robots are systems that often operate thanks to the processing of vast amounts of personal data. A robot for the blind might process sensitive health data (the person's health condition) about the owner, other categories of data (e.g., real-time location, eating habits, object position for obstacle-avoidance, metadata), and other persons (contact information, relevant caregivers). Moreover, a robot might use cloud services that speed the processing of such an amount of information, enlarging this way the amount of stakeholders involved in the collection and processing of data (Fosch-Villaronga and Millard 2019). Protection from the adverse effects that such processing might have on individuals was one of the main objectives of the GDPR. However, robots are constructed systems that process much information, exert direct control over the physical world, and might cause harm in a way that humans cannot necessarily correct or oversee well beyond a mere data protection infringement (Floridi 2016; Fosch-Villaronga and Millard 2019).

Floridi (2016) argues that the foundation for the right to data protection and the right to privacy GDPR aims to uphold is the concept of 'human dignity.' While not directly grounding itself in human dignity, the General Data Protection Regulation (GDPR 2016) stresses the idea to "include suitable and specific measures to safeguard the data subject's human dignity." The GDPR contains, however, two assumptions: (1) that the data subject is a human being, whose dignity needs to be safeguarded (a legal person could not enjoy human dignity); and (2) that human dignity is different from "legitimate interests and fundamental rights (Floridi 2016). In a similar line, the European Data Protection Supervisor (EDPS) stated:

"Privacy is an integral part of human dignity, and the right to data protection was originally conceived in the 1970 s and 80 s as a way of compensating the 
potential for the erosion of privacy and dignity through large scale personal data processing."

Floridi is not the first scholar to suggest that privacy was grounded in the concept of 'human dignity.' Legal scholars have widely discussed such a "dignitarian" approach to data protection (Lynskey 2015). However, some academics argue that although data protection provides sound principles, many socio-technical challenges presented by robot technologies, are not wholly dealt with in the concrete provisions of the GDPR (Cath 2018; Winfield and Jirotka 2018; Veale et al. 2018). While data protection legislation aims to protect personal data, the potential threats of robotics often go beyond that and include interference with the autonomy of individuals that does not depend on the collection of personal data. The use and development of robot technology question other aspects than mere data protection, such as physical and psychological integrity, responsibility, or autonomy (Fosch-Villaronga 2019).

Indeed, robots are not mere data-driven technologies. Robots have a physical embodiment that plays a significant role in several applications (Dautenhahn et al. 2002; Jung and Lee 2004) and can sense, think, and act to perform tasks. Bearing in mind the shortcomings of GDPR, it would be probably wrong to consider data protection as the ultimate governance solution for human-robot interactions, as other aspects would fall outside of the protected scope of such regulations.

\subsection{Technology Ethics}

Failure of concrete provisional legislation to regulate all aspects of robotics has often been used to justify technological inevitability, inferring that law (in general rather than specific statues of legislation) is not able to keep up with technology (Holder et al. 2016; Guihot et al. 2017; Fosch-Villaronga et al. 2019). Such rhetoric of the pacing problem (Marchant et al. 2011) is troubling, as it often fails to grasp the value of law and risks subordination of social structure to the worldview of a small group of profit-oriented individuals at the frontier of technology (Zuboff 2019).

The modern Western world formed around the laws that confer human rights and acknowledge the sanctity of each life (Frank, 1999). These formal laws were agreed upon based on the shared aspired values and were expressed as new demands to make actual in everyday life (Beck and Beck-Gernsheim 2002). Therefore, alongside the rapid development of robotics, articles, and policy documents addressing its governance proliferate in parallel. Some of these initiatives seem to suggest 'ethics' as the solution for ensuring the responsible use of robotics, as they understand that ethical values are underpinning the law that is often too rigid to change.

On its 'principles for responsible stewardship of trustworthy AI,' the Organisation for Economic Co-operation and Development (OECD) noted that the appropriateness of some of the legal and regulatory frameworks may need to be reassessed and new approaches developed respecting the rule of law, human rights and democratic values, such as human dignity (OECD 2019). While this recommendation tasks the Committee on Digital Economy Policy (CDEP) to monitor the implementation of 
these standards across jurisdictions, it recognizes the need for further practical guidance for operationalizing these standards.

The European institutions seem to gear the discussions revolving around the regulation of robotics and $\mathrm{AI}$ in a more actionable way. One of the most comprehensive and broadly discussed documents of technology ethics is the AI Ethics Guidelines (hereafter "HLEG guidelines") published by the High-level expert group on Artificial Intelligence (High-Level Expert Group on Artificial Intelligence 2019) set up by the European Commission.

The guidelines ground directly into human dignity:

"The common foundation that unites these rights can be understood as rooted in respect for human dignity - thereby reflecting what we describe as a "human-centric approach" in which the human being enjoys a unique and inalienable moral status of primacy in the civil, political, economic and social fields."

The HLEG guidelines suggest that 'human dignity' is an absolute value that cannot be subject to any intervention and balancing exercise (like, for instance, data protection cases) and that it encompasses the intrinsic worth of every human, which no new technology or any other person should ever diminish, compromise or repress. Other bodies, such as private standards organizations like IEEE, also acknowledge the importance of designing autonomous and intelligent systems in a way that they 'respect and fulfill human rights, freedoms, human dignity, and cultural diversity'(IEEE 2018). Still, there are no enforceable standards in place stressing the idea that dignity is the core value from which the subsequent to-be-respected rights emanate.

While the HLEG AI guidelines provide hints to what may be considered a violation of 'human dignity' in terms of human-robot interactions (violating human's physical/mental integrity), it does not explicitly state which applications involve such violations. In this sense, some authors indicate that (soft) ethical solutions suffer from conceptual ambiguity and lack of enforcement mechanisms, arguing that creating strong ethical principles is only the first step and that more should be done to assure implementation and accountability (Winfield and Jirotka 2018). Others believe that it constitutes an ethics washing exercise (Wagner 2018; Metzinger 2019), while others stress that this is better than not taking ethics into consideration all together (WEF 2019).

\section{Dignity as an overarching concept for the governance of robotics}

All these governance instruments, such as general technology ethics, humancentric design, safety standards, or data protection rules, intended to guide the technological developments for organizing a rapidly transforming society for adhering to its values. However, as these individual instruments often tackle the limited scope of the values, currently, there is no overarching instrument providing the omnibus governance solution for using robots in healthcare and of (robotics in general). For instance, safety standards for the use of robot-technology 
in healthcare consider the physical and mental integrity of individuals about human-robot interactions, leaving out a morally salient aspect of the privacy of users. Also, while data protection rules provide enforceable rules for safeguarding privacy during human-robot interactions, it scopes itself with the processing of personal data, leaving out the various issues such as long-term consequences of use of robotics in healthcare (e.g., loneliness).

As binding rules are limited and can not cover all the issues raised by human-robot interactions, there is a proliferation of articles and policy documents about the governance of robotics that seems to suggest 'ethics' as the solution for ensuring the responsible use of robots. Such issues are safety, allocation of responsibility, privacy, autonomy, objectification (also deception, and infantilization), increased loneliness, dependency, or other long-term consequences. While ethics helps us understand 'good' and 'bad' applications of robot technology, it lacks enforceability. They are often ambiguous and are criticized for avoiding red lines, provide 'ethics-washing,' and transform fundamental rights into 'potential rights' (Wagner 2018). Therefore, even though ethical considerations are valuable, 'roboethics' cannot be an omnibus governance solution for the use of healthcare in robotics, due to ambiguity and lack of enforceability.

Therefore, shortcomings of rules (e.g., safety, data protection) and roboethics, trigger the need for an overarching conceptual legal instrument that, at the same time, is flexible. This article argues that human dignity is the essence of what is being pressured by the use of robotics for healthcare. Human dignity is a general principle of law and inviolable value that all fundamental rights are grounded. At the same time, it combines various ethical considerations in one conceptual framework. While we have shown in Sect. 2 of this article that the concept of human dignity already has the content that may scope the use of robotics in healthcare, we argue that in the absence of adequate formal rules might confound this concept 'into a formless void of sentiment and intuition' (Allsop 2016). Therefore, this binding nature, on the one hand, and flexibility on the other suggests that human dignity can serve as a lens through which existing governance instruments are re-evaluated, combined, and new regulation formulated that is overarching governance solution based on human dignity.

In the human rights context, human dignity (that in this article is seen as the foundational belief that all human rights are grounded, rather than separate human right) can be read as a negative obligation restricting states from violating the dignity of their citizens. However, the need to apply human rights horizontally has been apparent as private entities are increasingly accumulating knowledge and power (Kanalan 2016). In cases where private actors fail to take responsibility to act per human rights, the framework ascribes a positive obligation to states to safeguard human dignity in horizontal relationships. Therefore, this article provides policy advice for the states in the first place, to provide governance of robotics through the lens of human dignity. This will require further, more comprehensive exploration of what such a flexible concept of human dignity entails in contemporary (and ever-evolving) society, and how can robotics challenge this notion. 


\section{Conclusion}

In this article, we reviewed some applications of robot technology in the healthcare domain from the lens of human dignity. We identified how these applications might promote or pressure human dignity. In general, the integration of robot technologies in healthcare provides a practical, complementary solution to address the increasing demand for care services. Robot technology could counterbalance the problems arising from the shortage of healthcare professionals and could be a good way to promote safer, more efficient, and personalized care. If done correctly, new healthcare applications of robot technology can support individuals in gaining back the 'dignity' that their condition took away and that current healthcare services never provided.

On the other hand, technology has broader, not always foreseeable consequences, and robot technology may also have an effect on human nature that we currently cannot anticipate. Moreover, recent findings suggest that some applications risk not treating humans as moral subjects, but mere objects that can be conditioned or manipulated. If these risks are not addressed, and the applications are not reconsidered, the violation of human dignity seems inevitable. Recent literature also highlights that technology might have unintended long-term harmful impacts on the human psyche, in particular on the way the brain works and the person's identity and self-respect, and this also questions whether these technologies are adequate for care purposes.

Lastly, we addressed the individual approaches to regulating the use of robots in healthcare and highlighted their shortcomings in providing overarching governance solutions for robotics. We argued that while the scope of data protection and safety rules are too limited, the ethics approach lacks enforceability and clarity. We stress the need for absolute protection of human dignity in the context of robot technology, especially if deployed in healthcare settings. Human dignity is the ultimate, overarching legal concept upon which all the rights are based and should be the basis of future legal intervention aimed at addressing the governance of robot technology, especially for healthcare. Therefore, we conclude by giving the policy advice to formulate an overarching, omnibus governance solution for robotics that will be based on the concept of human dignity. With this in mind, we acknowledge that furthermore, detailed research is necessary to clarify what dignity means in this connected, ever-evolving, and at the same time, diverse contemporary society and how the uses of robotics may challenge this notion.

Acknowledgements The research of the first author is part of the SCALES project in the research programme Responsible Innovation (MVI) with Project Number 313-99-315. This programme is financed by the Netherlands Organisation for Scientific Research (NWO). Second author acknowledges that part of this project is funded by the LEaDing Fellows Marie Curie COFUND fellowship, a project that has received funding from the European Union's Horizon 2020 research and innovation programme under the Marie Skłodowska-Curie Grant Agreement No. 707404.

Open Access This article is licensed under a Creative Commons Attribution 4.0 International License, which permits use, sharing, adaptation, distribution and reproduction in any medium or format, as long as you give appropriate credit to the original author(s) and the source, provide a link to the Creative 
Commons licence, and indicate if changes were made. The images or other third party material in this article are included in the article's Creative Commons licence, unless indicated otherwise in a credit line to the material. If material is not included in the article's Creative Commons licence and your intended use is not permitted by statutory regulation or exceeds the permitted use, you will need to obtain permission directly from the copyright holder. To view a copy of this licence, visit http://creativecommons.org/ licenses/by/4.0/.

\section{References}

Allsop, J. (2016). Values in law: How they influence and shape rules and the application of law. Lawasia $J$, p. 125.

Assembly, U. G. (1948). Universal declaration of human rights. UN General Assembly, 302(2).

Athlin, E., Norberg, A., \& Asplund, K. (1990). Caregivers' perceptions and interpretations of severely demented patients during feeding in a task assignment system. Scandinavian Journal of Caring Sciences, 4(4), 147-156.

Beck, U., \& Beck-Gernsheim, E. (2002). Institutionalized individualism and its social and political consequences. Ann Arbor: University of Michigan Press. Retrieved from: https://pdfs.semanticscholar .org/587d/7897bf2629a4e6a0fba2c48b87a55166fa6e.pdf.

Bremhorst, A., Mongillo, P., Howell, T., \& Marinelli, L. (2018). Spotlight on assistance dogs-legislation, welfare and research. Animals, 8(8), 129.

Broom, D. M. (2017) Animal Welfare in the European Union, DG for Internal Policies. Retrieved from: https://www.europarl.europa.eu/RegData/etudes/STUD/2017/583114/IPOL_STU(2017)583114_ EN.pdf. Accessed 8 Oct 2019.

Canal, G., Alenyà, G., \& Torras, C. (2016, November). Personalization framework for adaptive robotic feeding assistance. In International Conference on Social Robotics (pp. 22-31), Cham: Springer.

Carr, N. (2010). The shallows. What the internet is doing to our brains. New York: WW Norton \& Co.

Cath, C. (2018). Governing artificial intelligence: ethical, legal and technical opportunities and challenges. Philosophical Transactions Royal Society A, 376, 2133.

Childress, J. F., \& Beauchamp, T. L. (2001). Principles of biomedical ethics. New York: Oxford University Press.

Civil Law Rules on Robotics European Parliament resolution of 16 February 2017 with recommendations to the Commission on Civil Law Rules on Robotics (2015/2103(INL)).

Colby, K. M. (1981). Modeling a paranoid mind. Behavioral and Brain Sciences, 4(4), 515-534.

Colors, H. P., \& Tachi, S. Guide dog robot (MELDOG). https://tachilab.org/projects/meldog.html. Accessed 9 Oct 2019.

Council of Europe. (2018). European convention on human rights. 1950. Accessed 8.

Dautenhahn, K., Ogden, B., \& Quick, T. (2002). From embodied to socially embedded agents-implications for interaction-aware robots. Cognitive Systems Research, 3(3), 397-428.

Di Nucci, E. (2017). Sexual rights, disability, and sex robots. In J. Danaher \& N. McArthur (Eds.), Robot sex: Social and ethical implications (pp. 73-88). Cambridge: MIT Press.

Dicke, K. (2002). The founding function of human dignity in the universal declaration of human rights. In D. Kretzmer \& E. Klein (Eds.), Concept of human dignity in human rights discourse (pp. 111120). New York: Columbia University Press.

Dworkin, R. (2011). Justice for hedgehogs. Cambridge: Harvard University Press.

European Commission. (2018). Communication on Enabling the digital transformation of health and care in the Digital Single Market; empowering citizens and building a healthier society, Brussels, 25.4.2018, COM(2018) 233 final.

Fiske, A., Henningsen, P., \& Buyx, A. (2019). Your robot therapist will see you now: Ethical implications of embodied artificial intelligence in psychiatry, psychology, and psychotherapy. Journal of medical Internet research, 21(5), e13216.

Fitter, N., Funke, R., Pascual, J. C. P., Eisenman, L. E., Deng, W., Rosales, M. R., et al. (2019). Socially assistive infant-robot interaction: Using robots to encourage infant leg-motion training. IEEE Robotics and Automation Magazine, 26(2), 12-23.

Floridi, L. (2016). On human dignity as a foundation for the right to privacy. Philosophy \& Technology, 29(4), 307-312. 
Fosch-Villaronga, E. (2019). Robots, healthcare, and the law: Regulating automation in personal care. Routledge.

Fosch-Villaronga, E., \& Albo-Canals, J. (2019). "I'll take care of you", said the robot. Paladyn, Journal of Behavioral Robotics, 10(1), 77-93.

Fosch-Villaronga, E., \& Golia, A., Jr. (2019). Robots, standards and the law: Rivalries between private standards and public policymaking for robot governance. Computer Law \& Security Review, 35(2), 129-144.

Fosch-Villaronga, E., \& Heldeweg, M. (2018). "Regulation, I presume?" said the robot-Towards an iterative regulatory process for robot governance. Computer law \& security review, 34(6), 1258-1277.

Fosch-Villaronga, E., \& Millard, C. (2019). Cloud robotics law and regulation: Challenges in the Governance of complex and dynamic cyber-physical ecosystems. Robotics and Autonomous Systems, 119, 77-91.

Fosch-Villaronga \& Poulsen, A. (2019) Sex care robots. Exploring the potential use of sex robots for disabled and eldercare. Paladyn Journal of Behavioral Robotics, forthcoming.

Fosch-Villaronga, E., Lutz, C., \& Tamò-Larrieux, A. (2019). Gathering expert opinions for social robots' ethical, legal, and societal concerns: Findings from four international workshops. International Journal of Social Robotics, 1-18. https://doi.org/10.1007/s12369-019-00605-z.

Frank, T. M. (1999). The empowered self: Law and society in an age of individualism. Oxford: Oxford University Press.

Glendon, M. A. (2001). A world made new: Eleanor Roosevelt and the Universal Declaration of Human Rights. New York: Random House Trade Paperbacks.

Guihot, M., Matthew, A. F., \& Suzor, N. P. (2017). Nudging robots: Innovative solutions to regulate artificial intelligence. Vanderbilt Journal of Entertainment \& Technology Law, 20, 385.

Herlant, L. V. (2018) Algorithms, implementation, and studies on eating with a shared control robot arm. Doctoral dissertation, Robotics institute, Carnegie Mellon University, 2018. https://pdfs.semanticsc holar.org/b3e3/c9c792765ca10e8b10cb662abbd2e24c93d1.pdf. Accessed 8 Oct 2019.

High-Level Expert Group on Artificial Intelligence, HLEG-AI. (2019). Ethics guidelines for trustworthy AI. Brussels: European Commission.

Holder, C., Khurana, V., Harrison, F., \& Jacobs, L. (2016). Robotics and law: Key legal and regulatory implications of the robotics age (Part I of II). Computer Law \& Security Review, 32(3), 383-402.

Howard, A., Tapus, A., \& Kajitani, I. (2019). Socially assistive robots, guest editors. IEEE Robotics and Automation Magazine, 26(2), 10-110.

Howel, T., Bennett, P., Shiell, A. (2017) Reviewing assistance animal effectiveness: Literature review, provider survey, assistance animal owner interviews, health economics analysis and recommendations. Final Report to National Disability Insurance Agency. Retrieved from https://scholars.latro be.edu.au/display/publication228118. Accessed 8 Oct 2019.

ICCPR Second Optional Protocol. (1989). Aiming at the abolition of the death penalty, GA Res 44/128. https://www.ohchr.org/en/professionalinterest/pages/2ndopccpr.aspx. Accessed 8 Oct 2019.

IEEE. (2018). Ethically aligned design: A vision for prioritizing human well-being with autonomous and intelligent systems (A/IS). Retrieved from https://standards.ieee.org/content/dam/ieee-standards/ standards/web/documents/other/ead_v2.pdf. Accessed 9 Dec 2019.

Jung, Y., \& Lee, K. M. (2004). Effects of physical embodiment on social presence of social robots. In Proceedings of PRESENCE, (pp. 80-87).

Kanalan, I. (2016). Horizontal effect of human rights in the era of transnational constellations: On the accountability of private actors for human rights violations. In European Yearbook of International Economic Law 2016 (pp. 423-460). Cham: Springer.

Koops, B. J., \& Leenes, R. (2014). Privacy regulation cannot be hardcoded. A critical comment on the 'privacy by design' provision in data-protection law. International Review of Law, Computers \& Technology, 28(2), 159-171.

Lacey, G., \& Dawson-Howe, K. M. (1998). The application of robotics to a mobility aid for the elderly blind. Robotics and Autonomous Systems, 23(4), 245-252.

Leenes, R., \& Lucivero, F. (2014). Laws on robots, laws by robots, laws in robots: regulating robot behaviour by design. Law, Innovation and Technology, 6(2), 193-220.

Leite, I., Martinho, C., \& Paiva, A. (2013). Social robots for long-term interaction: a survey. International Journal of Social Robotics, 5(2), 291-308.

Leroux, C. \& Labruto, R. (2012). Ethical Legal and Societal issues in robotics, euRobotics The European Robotics Coordination Action. https://www.researchgate.net/profile/Christophe_Leroux/publicatio 
n/310167726_Ethical_Legal_and_Societal_issues_in_robotics/links/5829f77008ae138f1bf2fe4b. pdf. Accessed 8 Oct 2019.

Lusti-Narasimhan, M., \& Beard, J. R. (2013). Sexual health in older women. Bulletin of the World Health Organization, 91, 707-709.

Lynskey, O. (2015). The foundations of EU data protection law. Oxford: Oxford University Press.

Marchant, G. E., Allenby, B. R., \& Herkert, J. R. (Eds.). (2011). The growing gap between emerging technologies and legal-ethical oversight: The pacing problem (Vol. 7). Berlin: Springer Science \& Business Media.

Martinsen, B., Harder, I., \& Biering-Sorensen, F. (2008). The meaning of assisted feeding for people living with spinal cord injury: A phenomenological study. Journal of Advanced Nursing, 62(5), 533-540.

Maxwell, J., Belser, J. W., \& David, D. (2006). A health handbook for women with disabilities. California: Hesperian.

McCrudden, C. (2008). Human dignity and judicial interpretation of human rights. European Journal of international Law, 19(4), 655-724.

Metzinger, T. (2019). EU guidelines: Ethics washing made in Europe. Der Tagesspeigel. Retrieved from: https://www.tagesspiegel.de/politik/eu-guidelines-ethics-washing-made-ineurope/24195496.html.

Neuman, G. L. (2000). Human dignity in United States constitutional law. In D. Simon \& M. Weiss (Eds.), Zur Autonomie des Individuums (pp. 249-271). Baden-Baden: Liber Amicorum Spiros Simitis.

Nevejans, N. (2016). European civil law rules in robotics. Study. DG for internal policies. Retrieved from https://www.europarl.europa.eu/RegData/etudes/STUD/2016/571379/IPOL_STU(2016)571379_ EN.pdf. Accessed 9 Dec 2019.

Nussbaum, M. C. (2009). Frontiers of justice: Disability, nationality, species membership. Cambridge: Harvard University Press.

O'Mahony, C. (2012). There is no such thing as a right to dignity. International Journal of Constitutional Law, 10(2), 551-574.

OECD (2019). Recommendation of the Council on Artificial Intelligence. Retrieved from https://legalinstr uments.oecd.org/en/instruments/OECD-LEGAL-0449. Accessed 09 Dec 2019.

Palmerini, E., Azzarri, F., Battaglia, F., Bertolini, A., Carnevale, A., Carpaneto, J., Warwick, K, (2014) Guidelines on Regulating Robotics. RoboLaw: Regulating Emerging Robotic Technologies in Europe. Retrieved from http://www.robolaw.eu/RoboLaw_files/documents/robolaw_d6.2_guide linesregulatingrobotics_20140922.pdf. Accessed 9 Dec 2019.

Pulido, S. D., Bocanegra, Á. J., Cancino, S. L., \& López, J. M. (2019). Serious game controlled by a human-computer interface for upper limb motor rehabilitation: A feasibility study. In Iberian Conference on Pattern Recognition and Image Analysis (pp. 359-370). Cham: Springer.

Reardon, C., Zhang, H., Wright, R., \& Parker, L. E. (2019). Robots can teach students with intellectual disabilities educational benefits of using robotic and augmented reality applications. IEEE Robotics and Automation Magazine, 26(2), 79-93.

Rosen, L. D., Lim, A. F., Felt, J., Carrier, L. M., Cheever, N. A., Lara-Ruiz, J. M., et al. (2014). Media and technology use predicts ill-being among children, preteens and teenagers independent of the negative health impacts of exercise and eating habits. Computers in Human Behavior, 35, 364-375.

Schroeder, D., \& Bani-Sadr, A. H. (2017). Dignity in the 21st century: Middle east and west. Berlin: Springer International Publishing.

Sharkey, A. (2014). Robots and human dignity: A consideration of the effects of robot care on the dignity of older people. Ethics and Information Technology, 16(1), 63-75.

Shultziner, D. (2007). Human dignity: Functions and meanings. Perspectives on human dignity: A conversation (pp. 73-92). Dordrecht: Springer.

Tachi, S., \& Komoriya, K. (1984). Guide dog robot. Autonomous mobile robots: Control, planning, and architecture, (pp. 360-367).

Tapus, A., Bandera, A., Vazquez-Martin, R., \& Calderita, L. V. (2019). Perceiving the person and their interactions with the others for social robotics-A review. Pattern Recognition Letters, 118, 3-13.

Temmerman, M., Khosla, R., \& Say, L. (2014). Sexual and reproductive health and rights: A global development, health, and human rights priority. The Lancet, 384(9941), e30-e31.

Tsang, M. F. (2008). Is there adequate feeding assistance for the hospitalised elderly who are unable to feed themselves? Nutrition \& Dietetics, 65(3), 222-228.

Tucker, M. R., Shirota, C., Lambercy, O., Sulzer, J. S., \& Gassert, R. (2017). Design and characterization of an exoskeleton for perturbing the knee during gait. IEEE Transactions on Biomedical Engineering, 64(10), 2331-2343. 
United Nations (1993a) The Cairo Declaration of Human Rights. A/CONF.157/PC/62/Add.18. https:// undocs.org/A/CONF.157/PC/62/Add.18. Accessed 8 Oct 2019.

United Nations (1993b) Standard rules on the equalization of opportunities for persons with disabilities. https://www.un.org/documents/ga/res/48/a48r096.htm. Accessed 9 Oct 2019.

United Nations. (2007). Convention on the rights of persons with disabilities. https://www.un.org/devel opment/desa/disabilities/convention-on-the-rights-of-persons-with-disabilities.html. Accessed 8 Oct 2019.

Vallor, S. (2011). Carebots and caregivers: Sustaining the ethical ideal of care in the twenty-first century. Philosophy \& Technology, 24(3), 251.

Vandemeulebroucke, T., de Casterle, B. D., \& Gastmans, C. (2018). The use of care robots in aged care: A systematic review of argument-based ethics literature. Archives of Gerontology and Geriatrics, $74,15-25$.

Veale, M., Binns, R., \& Edwards, L. (2018). Algorithms that remember: Model inversion attacks and data protection law. Philosophical Transactions of the Royal Society A: Mathematical, Physical and Engineering Sciences, 376(2133), 20180083.

Vienna Declaration and Programme of Action. (1993). World Conference on Human Rights, Vienna, (pp. 14-25) https://www.ohchr.org/en/professionalinterest/pages/vienna.aspx.

Wagner, B. (2018). Ethics as an escape from regulation: From ethics-washing to ethics-shopping? In M. Hildebrandt (Ed.), Being profiling. Cogitas ergo sum (pp. 84-90). Amsterdam: Amsterdam University Press.

Weisstub, D. N. (2002). Honor, dignity and the framing of multiculturalist values. In D. Kretzmer \& E. Klein (Eds.), Concept of human dignity in human rights discourse (pp. 263-294). Columbia: Columbia University Press.

Weizenbaum, J. (1976). Computer power and human reason: From judgment to calculation. San Francisco: W. H. Freeman and Company.

White, A., \& Parotto, M. (2019). Families in the intensive care unit: A guide to understanding, engaging, and supporting at the bedside. Anesthesia and Analgesia, 129(3), e99.

Winfield, A. F., \& Jirotka, M. (2018). Ethical governance is essential to building trust in robotics and artificial intelligence systems. Philosophical Transactions of the Royal Society A: Mathematical, Physical and Engineering Sciences, 376(2133), 20180085.

World Economic Forum, WEF. (2019). AI governance: A holistic approach to implement ethics into AI. Retrieved from: https://weforum.my.salesforce.com/sfc/p/\#b0000000GycE/a/0X000000cP 11/i.8ZWL2HIR_kAnvckyqVA.nVVgrWIS4LCM1ueGy.gBc.

World Health Organization, WHO. (2018). Ageing and health. https://www.who.int/news-room/fact-sheet s/detail/ageing-and-health. Accessed 8 Oct 2019.

Zuboff, S. (2019). The age of surveillance capitalism: The fight for a human future at the new frontier of power. London: Profile Books.

Publisher's Note Springer Nature remains neutral with regard to jurisdictional claims in published maps and institutional affiliations. 